\title{
O Estabelecimento de Vínculos entre Cuidadores e Crianças no Contexto das Instituições de Acolhimento: um Estudo Teórico
}

\author{
Blenda Carine Dantas de Medeiros \\ Universidade Estadual Paulista (Unesp), SP, Brasil.
}

\author{
João Batista Martins \\ Universidade Estadual Paulista (Unesp), SP, Brasil.
}

Resumo: O presente artigo tem como foco a realização de uma discussão teórica acerca do trabalho dos cuidadores residentes, atuantes em instituições de acolhimento na modalidade casa-lar, e busca contemplar as especificidades próprias ao trabalho realizado diretamente com crianças e adolescentes acolhidos, tanto no que diz respeito aos documentos normativos que fundamentam as práticas voltadas ao cumprimento dessa medida protetiva, como também em relação às vivências cotidianas dos cuidadores e às relações estabelecidas com os sujeitos acolhidos e seus familiares. Para isso, realizamos um breve resgate teórico acerca das políticas de acolhimento para crianças e adolescentes no Brasil, seguido de uma análise das produções acadêmicas que apontam aspectos das relações estabelecidas nesses espaços de acolhimento, a partir de pesquisas bibliográficas realizadas nos bancos de dados Parthenon e Biblioteca Digital Brasileira de Teses e Dissertações (BDTD), com os seguintes descritores: "mãe social", "mães sociais", "cuidador* resident*" e "acolhimento", em combinações diferentes e variando os campos de busca. A leitura dos artigos, teses e dissertações nos possibilitaram discutir algumas questões relativas ao trabalho de cuidadores residentes e ao estabelecimento de vínculos com as crianças e adolescentes acolhidos, com destaque para os tensionamentos vivenciados por esses profissionais, que podem levá-los ao adoecimento decorrente de seu trabalho. Com mais questionamentos que esclarecimentos, fica a certeza da urgência em se voltar o olhar para a identidade profissional e pessoal dos cuidadores residentes, que assumem profissionalmente um lugar de referência afetiva constante e um acompanhamento diário de crianças e adolescentes em situação acolhimento.

Palavras-chave: Cuidador Residente, Acolhimento Institucional, Casa-lar.

\section{The Establishment of Bond between Caregivers and Children in the Context of Fostering Institutions: a Theoretical Study}

\begin{abstract}
This article focuses on a theoretical discussion about the work of the resident caregivers, who work in home-based care institutions taking care of children and teenagers. The article aims to analyze the normative documents on which are based the practices of those professionals in relation to those children and their families, and to study the daily experiences of the caregivers. Thus, we did a brief theoretical review on the policies of reception for children and teenagers in Brazil, followed by an analysis of the academic productions that point out aspects regarding the relations established in these reception spaces, based on bibliographical research made in the Parthenon and BDTD, with the following descriptors: "mãe social", "mães sociais", "cuidador* resident" and "acolhimento", in different combinations and varying the search fields. The reading of the articles, thesis and dissertations allowed us to discuss some issues related to the work of resident caregivers and the establishment of bond with children and adolescents hosted, highlighting the tensions experienced by these professionals, which can lead to illness due to their job. With more questions than clarifications, the urgency to look at the professional and personal identity of the resident caregivers, who professionally assume a constant affective reference point and a daily follow-up of children and adolescents in a foster care situation, is assured.
\end{abstract}

Keywords: Resident Caregiver, Institutional Care, Home. 


\title{
El Establecimiento de Vínculos entre Cuidadores y Niños en el Contexto de las Instituciones de Acogida: un Estudio Teórico
}

\begin{abstract}
Resumen: El presente artículo tiene como foco la realización de una discusión teórica acerca del trabajo de los cuidadores residentes, actuantes en instituciones de acogida en la modalidad casa-hogar, buscando contemplar las especificidades propias del trabajo realizado directamente con niños y adolescentes acogidos, tanto en lo que se refiere a los documentos normativos que fundamentan las prácticas dirigidas al cumplimiento de esa medida protectora, así como en relación a las vivencias cotidianas de los cuidadores y las relaciones establecidas con los sujetos acogidos y sus familiares. Para ello, realizamos un breve rescate teórico acerca de las políticas de acogida para niños y adolescentes en Brasil, seguido de un análisis de las producciones académicas que apuntan aspectos de las relaciones establecidas en esos espacios, a partir de investigaciones bibliográficas realizadas en los bancos de datos Parthenon y La Biblioteca Digital Brasileña de Tesis y Disertaciones (BDTD), con los siguientes descriptores: " madre social", " madres sociales", "cuidador* resident* " y "acogida”, en combinaciones diferentes y variando los campos de búsqueda. La lectura de los artículos, tesis y disertaciones nos posibilitaron discutir algunas cuestiones relativas al trabajo de cuidadores residentes y al establecimiento de vínculos con los niños y adolescentes acogidos, con destaque para las contradicciones vividas por esos profesionales y que pueden llevarlos a la enfermedad debido a su trabajo. Con más cuestionamientos que aclaraciones, queda la certeza de la urgencia en volver la mirada hacia la identidad profesional y personal de los cuidadores residentes, que asumen profesionalmente un lugar de referencia afectiva constante y un acompañamiento diario de niños y adolescentes en situación de acogida.
\end{abstract}

Palabras clave: Cuidador Residente, Acogida Institucional, Casa-hogar.

\section{Introdução}

Para discutir as práticas profissionais de cuidadores no âmbito das instituições de acolhimento, as quais estão voltadas à garantia de direitos de crianças e adolescentes, precisamos resgatar alguns aspectos desse processo histórico, que se intensificou no Brasil principalmente a partir da década de 1980. Cabe destacar, primeiramente, que tanto as garantias pensadas para esse grupo quanto as práticas sociais que permitirão sua efetivação apresentam-se relacionadas com as concepções de infância e de criança adotadas por aqueles que formulam tais garantias.

A busca pela defesa e garantia de direitos de crianças e adolescentes - especialmente pelo fato de a concepção de criança enquanto sujeito de direitos ter se tornado mais difundida - vem ganhando espaço de discussão e visibilidade, principalmente pela ação de movimentos sociais e dos profissionais envolvidos com essa população, como psicólogos, assistentes sociais, entre outros.
Rosemberg e Mariano (2010) destacam dois marcos fundantes da mudança paradigmática na concepção de infância, quais sejam: a promulgação da Declaração Universal dos Direitos da Criança, realizada pela Organização das Nações Unidas (ONU) em 1959, e o livro de Philippe Ariès, L'enfant et la vie familiale sous l'ancien régime ${ }^{1}$, publicado em 1961 e traduzido para diversos idiomas.

Para as autoras, "ambos os textos instalaram discursos e práticas sobre a infância e as crianças contemporâneas" (Rosemberg, \& Mariano, 2010, p. 694), exercendo assim uma influência considerável nesses discursos e práticas voltados à proteção e garantia de direitos de crianças e adolescentes nos últimos tempos. A publicação de Ariès, por exemplo, teria inaugurado uma visão de infância enquanto construção social, localizada em um tempo e espaço, e dependente do discurso intelectual vigente.

Essa nova perspectiva de compreensão da infância, publicizada em produções teóricas e também

${ }^{1}$ Traduzido para o português com o título "História Social da Criança e da Família". 
no âmbito sociopolítico, presente nos documentos acima elencados, acaba por consagrar um período de rompimento com outras tendências até então hegemônicas quanto ao modo de pensar a infância e as práticas sociopolíticas destinadas às crianças, as quais se pautavam, principalmente, por uma perspectiva de disciplinamento e dominação (Faleiros, \& Faleiros, 2007). O processo histórico que se dá com fins de garantir direitos e dignidade a esses sujeitos fica, pois, marcado tanto pela pressão de movimentos sociais em prol de uma infância mais protegida quanto pela apropriação, pelos países membros da ONU, de documentos internacionais que apontam diretrizes para as políticas sociais voltadas a este público.

Dentre as medidas que foram adotadas pelo Estado brasileiro para assegurar o bem-estar da criança e de suas famílias, o acolhimento institucional tem se configurado enquanto medida protetiva para crianças e adolescentes que precisam ser afastados do convívio familiar, principalmente quando se encontram em situação de risco e vulnerabilidade. Para a implementação de políticas desta natureza, bem como a superação de concepções de infância enquanto objeto de intervenção do Estado, busca-se enfatizar o paradigma da proteção integral de crianças e adolescentes, conforme o Estatuto da Infância e do Adolescente (ECA) (Lei n.8.069, 1990). Isto significa, primeiramente, considerá-los sujeitos. Eles devem, por sua vez, ser protegidos pelo Estado e a sociedade civil, que tem o dever de lhes garantir um ambiente em que seja possível um desenvolvimento saudável.

Nesse processo histórico, muitas são as instituições criadas com o fim de atender a crianças e adolescentes que necessitem de acolhimento. Para dar conta dessa demanda, tais instituições contratam profissionais que assumem o cargo de cuidadores, sendo os responsáveis diretos por aqueles que ficam sob sua proteção. Diante do caráter protetivo dessa medida, aqueles que fazem parte da instituição devem estar atentos ao cumprimento das diretrizes e às orientações que constam nos documentos legais.

As práticas realizadas nesses espaços de acolhimento precisam ser condizentes com tais documentos, devendo-se ter em conta as particularidades do desenvolvimento dos sujeitos acolhidos e as implicações que a vivência de situações de risco e de rompimento vivenciadas por eles tem para esse processo.

Nesse sentido, o presente artigo tem como foco a realização de uma discussão teórica acerca do traba- lho dos cuidadores residentes, que é própria à modalidade de acolhimento denominada casa-lar (Brasil, 2009), com atenção às vivências desses cuidadores e o estabelecimento de relações com os sujeitos sob sua responsabilidade.

Antes, porém, se faz necessário um resgate teórico acerca das políticas de acolhimento para crianças e adolescentes no Brasil, a partir dos documentos normativos que fundamentam as práticas voltadas ao cumprimento dessa medida protetiva. Com isso, poderemos realizar uma melhor discussão das produções acadêmicas que apontam aspectos das relações estabelecidas nesses espaços de acolhimento.

\section{$O$ acolhimento institucional de crianças e adolescentes no Brasil}

Historicamente, existiram várias instituições no Brasil que assumiram a função de cuidar e manter crianças e adolescentes que não tinham família ou não puderam permanecer, por diversos motivos, com seus responsáveis. Assim, temos desde as Casas de Expostos, comuns nos séculos XVIII e XIX, que recebiam bebês indesejados e crianças abandonadas, até os internatos do Serviço Nacional de Assistência aos Menores (SAM) e da Fundação Nacional do Bem-estar do Menor (Funabem), fundadas ao longo do século $\mathrm{XX}$, e que, apesar de destinados aos meninos considerados "perigosos", "suspeitos" ou “infratores", também funcionavam como espaço de acolhimento para os "menores" que não tinham famílias ou cujos pais não eram considerados capazes de se responsabilizar por seus cuidados e condutas (Faleiros, \& Faleiros, 2007).

Esse percurso histórico é marcado por um deslocamento do domínio da Igreja em relação ao cuidado com a criança, especialmente com os discursos e práticas das Casas de Caridade e rodas dos expostos, para o domínio do Estado, para o qual as crianças e adolescentes passam a ser objetos de intervenção, com instituições reguladoras da "causa da infância" (Perez, \& Passone, 2010, p. 653). Esse percurso, por sua vez, não é linear ou isento de conflitos; são discursos e práticas que passam a coexistir, variando inclusive a depender do campo de atuação e do grupo específico a que se destinam.

Inicialmente, a proteção das crianças "desvalidas" era revestida de um sentimento religioso de compaixão e caridade, aplicando-se uma prática assistencialista nas instituições destinadas ao cuidado desses sujeitos, difundindo-se, no Brasil, a prática de se criar filhos alheios (Marcilio, 1997). Sob essa perspectiva, é no âmbito pri- 
vado e das instituições religiosas que são ofertados cuidados para as crianças e adolescentes que necessitem.

Com a passagem do Impérioà República e uma forte influência do movimento higienista, a filantropia passa a ser defendida como modelo assistencial, em substituição ao modelo caritativo. A filantropia, a partir da associação com a ciência médica, o poder judiciário e as ações públicas, passa a organizar a assistência dentro das novas exigências sociais, políticas, econômicas e morais do século XX (Corrêa, 1997). A associação do movimento higienista e filantrópico para regulamentação das ações do Estado, sob a lógica da infância enquanto objeto de atenção e controle, levou a uma estratégia estatal que se prolongou nas décadas posteriores, cujas intervenções visavam menos a proteção à infância que a defesa da sociedade (Perez, \& Passone, 2010).

Assim, à medida que o paradigma da proteção integral passa a ser adotado, advém não ser mais suficiente apenas a caridade e a compaixão do outro para acolher crianças e adolescentes, tampouco a explicação higienista para internação compulsória de crianças e adolescentes pobres. Estabelece-se, por sua vez, um conjunto de critérios e disposições para que as instituições de acolhimento não firam princípios de garantia de direitos aos mesmos.

Passa a ser necessário atentar para uma série de diretrizes que levem em conta as especificidades do desenvolvimento desses sujeitos, o estabelecimento de relações estáveis e afetivas, e o suporte necessário para que se assegure tal processo.

Acerca das políticas sociais de atendimento a crianças e adolescentes no Brasil, Perez e Passone (2010) resumem esse percurso histórico, que pode muito bem representar o percurso das políticas de acolhimento:

A instituição da noção de direitos da infância e da adolescência, inicialmente inexistente e relegada ao trato do mundo do privilégio privado e religioso, posteriormente, incorporada por um Estado autoritário e monopolizador, que excluía qualquer forma de interlocução com a incipiente sociedade de então tem, paradoxalmente, representado há mais de dezoito anos uma pauta política e social que vem balizando o aprofundamento democrático das relações Estado-sociedade em torno da questão (p. 651).

No que tange ao acolhimento de crianças e adolescentes, temos uma série de documentos e normas que apresentam, de um modo geral, seções específicas acerca dos serviços de acolhimento. Desde o ECA, Lei Federal no 8.069/1990 (1990), às Diretrizes de Cuidados Alternativos à Criança, de âmbito internacional (ONU, 2009), encontramos diretrizes para as políticas públicas voltadas a este público, incluindo-se nelas referências para organização e funcionamento das instituições de acolhimento.

Vale ressaltar que tais marcos legais se encontram inter-relacionados, de modo a encontrarmos referências comuns entre elas, haja vista o esforço para efetivação das políticas públicas e serviços destinados à garantia de direitos de crianças e adolescentes. Alguns documentos, inclusive, derivam de propostas contidas em projetos anteriores. Como exemplo, podemos citar o artigo 227 da Constituição Federal de 1988 que se tornou a base para criação do Estatuto da Criança e do Adolescente (Lei n. 8.069, 1990).

Para citar uma intersecção mais recente, temos, enquanto resultado do cumprimento de uma ação prevista no Plano Nacional de Promoção, Proteção e Defesa do Direito de Crianças e Adolescentes à Convivência Familiar e Comunitária (PNCFC) (Brasil, 2006a), as Orientações Técnicas: Serviços de Acolhimento para Crianças e Adolescentes ${ }^{2}$, estabelecidas pelo Conselho Nacional dos Direitos da Criança e do Adolescente (Conanda) e pelo Conselho Nacional de Assistência Social (CNAS) (Brasil, 2009).

De acordo com as Orientações Técnicas (Brasil, 2009), os seguintes documentos devem pautar as ações dos serviços de acolhimento para crianças e adolescentes: ECA (Lei n. 8.069, 1990); PNCFC (Brasil, 2006a); Política Nacional de Assistência Social (Brasil, 2005); Norma Operacional Básica de Recursos Humanos, do Sistema Único de Saúde (SUAS) (Brasil, 2006b); Norma Operacional Básica do SUAS (Brasil, 2005); Projeto de Diretrizes das Nações Unidas sobre Emprego (ONU, 2007), e Cuidados Alternativos com Crianças (ONU, 2009).

A atenção a tais pressupostos deve ser efetivada, especialmente quando consideramos as normas elaboradas no âmbito do SUAS, haja vista que o acolhimento institucional faz parte dos Serviços de Alta Complexidade desse Sistema, isto é, o acolhimento institucional é uma das medidas de proteção previstas no ECA, destinada à criança e ao adolescente cujos direitos foram ameaçados ou violados (Lei n. 8.069, 1990).

${ }^{2}$ A partir de agora, mencionada apenas como Orientações Técnicas. 
Assim, conforme o PNCFC (Brasil, 2006a), em havendo a necessidade de afastamento da criança ou adolescente de sua família de origem com fins de proteção de sua integridade física e psicológica, os serviços de acolhimento a eles oferecidos devem lhes possibilitar condições favoráveis ao seu desenvolvimento, bem como os cuidados que forem necessários para isso. Essa medida protetiva deve se pautar pelos princípios da provisoriedade e excepcionalidade do acolhimento, de forma que o sujeito acolhido deve permanecer o mínimo de tempo possível na instituição, enquanto se viabiliza a reintegração à família de origem ou, não sendo possível, o encaminhamento para família substituta.

Os princípios estruturantes dos serviços de acolhimento também aparecem sistematizados e elencados em documentos mais recentes, mesmo já tendo sido problematizados nos textos do ECA e do PNCFC acima citados. Esses princípios são apresentados de forma sistemática nas Orientações Técnicas (Lei n. 8.069, 2009), a saber: excepcionalidade do afastamento do convívio familiar; provisoriedade do afastamento do convívio familiar; preservação e fortalecimento dos vínculos familiares e comunitários; garantia de acesso e respeito à diversidade e não discriminação; oferta de atendimento personalizado e individualizado; garantia de liberdade de crença e religião; respeito à autonomia da criança, do adolescente e do jovem.

Tendo em vista tais princípios, a equipe de profissionais responsáveis pelo acompanhamento da criança ou adolescente em situação de risco deve, inicialmente, realizar um estudo diagnóstico para que se identifique a necessidade ou não de afastamento do meio familiar - cujo relatório deve subsidiar inclusive a decisão judicial acerca do caso. Confirmando-se a necessidade de acolhimento institucional, essa equipe deverá identificar qual serviço disponível no município seria o mais adequado para tal.

Existem algumas modalidades de acolhimento possíveis de serem ofertadas aos sujeitos sob essa medida protetiva, quais sejam: os abrigos institucionais, as casas-lares e as famílias acolhedoras (Lei n. 8.069, 2009) que, apesar de apresentarem a mesma função, possuem suas peculiaridades quanto à forma de organização. No caso das famílias acolhedoras, o acolhimento acontece nas residências de famílias cadastradas para ofertar tal serviço; para isso, devem ser sempre acompanhadas por uma equipe técnica do órgão responsável da Assistência Social.

Apenas os abrigos institucionais ${ }^{3}$ e as casas-lares possuem funcionários específicos para prover os cuidados básicos aos sujeitos acolhidos, quais sejam os cuidadores e os auxiliares, além da coordenação e equipe técnica (Brasil, 2006a). Nas instituições que funcionam na modalidade casa-lar, por se constituírem residências com até dez sujeitos acolhidos, quando há mais de uma casa, há pelo menos um cuidador por casa-lar, mas apenas uma equipe técnica comum a todas.

Para ambas as modalidades de acolhimento, há diretrizes para que o trabalho realizado pela equipe $\mathrm{e}$ pelos cuidadores - que devem ser devidamente qualificados para isso - possa contribuir para redução das violações de direitos dos sujeitos acolhidos e de suas famílias, com inclusão dos mesmos em serviços da Assistência Social e consequente acesso a oportunidades que lhes possibilitem construção de autonomia e rompimento de ciclos de violência (Brasil, 2013). Em ambos os casos, fica estabelecido que cada profissional será responsável por até dez crianças e adolescentes acolhidos, com atividades voltadas à prestação de auxílio e apoio às crianças e adolescentes acolhidos, organização do ambiente, acompanhamento nos serviços do cotidiano.

A principal diferença que justifica a categorização em modalidades distintas de acolhimento diz respeito ao número de acolhidos por local, sendo no máximo dez por casa-lar e até 20 em cada abrigo institucional. São ainda atribuídos ao cuidador residente, ou seja, àquele que trabalha na modalidade casa-lar, a organização da rotina doméstica e do espaço residencial; os cuidados básicos com alimentação, higiene e proteção; e o estabelecimento de relação afetiva personalizada com cada criança e/ou adolescente (Brasil, 2009).

Como vemos, a atuação dos cuidadores residentes nas casas-lares se organiza em torno de ações que tem como ponto de partida um cuidar tangenciado, necessariamente, com os aspectos afetivos implicados nas relações. Será esta dimensão, especialmente vislumbrada nas atividades que implicam relações personalizadas e individualizadas com cada sujeito acolhido, o foco de nosso estudo.

\footnotetext{
${ }^{3}$ De acordo com o Plano Nacional de Convivência Familiar e Comunitária (Brasil, 2006a), o acolhimento institucional designa os programas de abrigo em entidade para crianças e adolescentes sob medida protetiva, conforme definido no ECA, e pode ser oferecido nas seguintes modalidades: Abrigo Institucional para pequenos grupos, Casa Lar e Casa de Passagem. Esta última sendo um acolhimento Institucional de curtíssima duração, onde se realiza diagnóstico eficiente sobre medidas mais adequadas para o sujeito.
} 


\section{Dos vínculos afetivos: normativas jurídicas e legais}

No que tange à relação que se estabelece para o cuidado com os sujeitos acolhidos e as especificidades desse trabalho nas instituições de acolhimento, o Projeto Político Pedagógico a ser construído para orientação das ações nesses espaços deve necessariamente abordar as atribuições dos cuidadores, educadores ou da família acolhedora - a depender do modelo de acolhimento empregado -, cujo papel é definido pelas Orientações Técnicas (Brasil, 2009) da seguinte forma:

Em função de sua importância, o educador/cuidador e a família acolhedora devem ter clareza quanto a seu papel: vincular-se afetivamente às crianças/adolescentes atendidos e contribuir para a construção de um ambiente familiar, evitando, porém, "se apossar" da criança ou do adolescente e competir ou desvalorizar a família de origem ou substituta. O serviço de acolhimento, não deve ter a pretensão de ocupar o lugar da família da criança ou adolescente, mas contribuir para o fortalecimento dos vínculos familiares, favorecendo o processo de reintegração familiar ou o encaminhamento para família substituta, quando for o caso (p. 47).

De forma a contemplar essas especificidades próprias ao trabalho realizado diretamente com crianças e adolescentes acolhidos, faz-se necessário o desenvolvimento de estratégias não só para uma adequada seleção dos profissionais que atuarão nesse espaço, mas também para seu processo de capacitação e o devido acompanhamento e supervisão, que devem ser realizados constantemente pelas equipes técnicas e serviços socioassistenciais.

Há, inclusive, um texto da ONU no qual são estabelecidas as orientações desejáveis para implementação de políticas e de práticas de proteção social, tendo por base a Convenção sobre os Direitos da Criança e outros instrumentos internacionais que tratam da proteção e do bem-estar das crianças impossibilitadas de permanecer sob cuidados parentais (ONU, 2009).

Neste texto, denominado Diretrizes de Cuidados Alternativos à Criança, consta uma série de cuidados alternativos, incluindo-se o acolhimento institucional, bem como as medidas apropriadas para prestação desses cuidados. As Diretrizes reforçam a necessidade de sensibilidade na interação com a criança que necessite de tais cuidados, cuja preparação para o trabalho deve ir além da atenção aos cuidados básicos diários.

Destaca-se, assim, a importância do papel dos cuidadores no desenvolvimento de relações positivas, seguras e fortalecedoras com as crianças, de modo tal que o sujeito que assume tal papel deve ser capaz de desempenhá-lo nestes termos (ONU, 2009). Conscientes de que as relações estabelecidas com as crianças e adolescentes acolhidos possibilita a construção de sentidos e de um repertório de comportamentos, Rossetti-Ferreira et al. (2012) elencam como uma das medidas que devem ser tomadas com relação ao trabalho realizado nos espaços de acolhimento: a "formação em serviço, supervisão e apoio às famílias acolhedoras e aos educadores e demais profissionais dos abrigos, que os posicione como 'parceiros' no trabalho de proteção às crianças e adolescentes" (p. 397).

O PNCFC, aprovado em 2006 (Brasil, 2006a), é mais um importante documento quando consideramos o trabalho com sujeitos acolhidos. Trata-se de um marco das políticas públicas para a infância no Brasil, de acordo com Costa e Rossetti-Ferreira (2009), posto que se propõe a romper com a cultura da institucionalização de crianças e adolescentes ao evidenciar o comprometimento com o reordenamento da política nacional de assistência com o foco na família, valorizando-a enquanto espaço ideal de convivência para a criança e o adolescente.

O referido Plano delineia as diretrizes nacionais para medidas específicas de apoio sociofamiliar, de acolhimento familiar e institucional e de adoção, buscando fortalecer o paradigma da proteção integral e a preservação dos vínculos familiares e comunitários, conforme estabelece o ECA.

Com relação à modalidade de acolhimento em que trabalham os cuidadores residentes, o PNCFC (Brasil, 2006a, p. 41) aponta que as casas-lares, definidas pela Lei $\mathrm{n}^{\circ} 7.644 / 1987$, "devem estar submetidas a todas as determinações do ECA relativas às entidades que oferecem programas de abrigo, anteriormente citadas, particularmente no que se refere à excepcionalidade e à provisoriedade da medida".

Acerca das especificidades do atendimento em casas-lares, as Orientações Técnicas também trazem informações importantes acerca da estrutura que devem adotar, qual seja de residências privadas, inseridas em bairros residenciais, havendo um cuidador residente em cada casa-lar, responsável por no máximo dez crianças e adolescentes, e que deve receber supervisão técnica para realização do seu trabalho. 
A lei anteriormente citada, qual seja a Lei $\mathrm{n}^{\circ} 7.644 / 1987$, dispõe sobre a regulamentação da atividade de mãe social e pai social e define, em seu Art. $4^{\circ}$, suas atribuições:

I - propiciar o surgimento de condições familiares adequadas, orientando e assistindo as crianças e os adolescentes sob seus cuidados;

II - administrar o lar, realizando e organizando as tarefas pertinentes;

III- dedicar-se, com exclusividade, às crianças e aos adolescentes e à casa-lar que lhes forem confiados. Parágrafo único. A mãe social e o pai social, no exercício de suas atribuições, devem residir na casa-lar, em companhia das crianças e adolescentes sob sua responsabilidade.

Segundo a Classificação Brasileira de Ocupações (Portaria n. 397, 2002), o cargo de mãe social pertence à família ocupacional de "Cuidadores de crianças, jovens, adultos e idosos”, para a qual é atribuída uma série de atividades que perpassa o cuidado com o outro, com sua saúde e educação, seu bem-estar, sua alimentação e com o ambiente domiciliar e institucional. Ressaltamos que as atribuições elencadas para este grupo estão em consonância com o exposto nas Orientações Técnicas para os serviços de acolhimento, como já relatamos.

Além disso, cabe destacar que as Orientações Técnicas (Brasil, 2009) indicam a substituição dos termos largamente utilizados mãe social ou pai social por educador(a) ou cuidador(a) residente, justificando essa alteração com vistas a evitar ambiguidade de papéis ou outras consequências de natureza análoga na percepção da criança ou adolescente acerca do acolhimento.

\section{Método de pesquisa}

Tendo em conta que este artigo se propõe a discutir as relações estabelecidas em instituições de acolhimento na modalidade casa-lar, a partir do trabalho que se realiza nesses espaços, buscamos as produções que já haviam sido publicadas acerca dessa temática, ou que traziam como um dos pontos de discussão o trabalho de cuidadores residentes ou mães sociais.
Assim, foram realizadas pesquisas bibliográficas em dois bancos de dados, quais sejam o Parthenon ${ }^{4}$ e a Biblioteca Digital Brasileira de Teses e Dissertações ${ }^{5}$ (BDTD), ambas realizadas no dia 5 de setembro de 2016 e utilizando os seguintes descritores: "mãe social", "mães sociais", "cuidador* resident ${ }^{* 6 ”}$ e "acolhimento", em combinações diferentes e variando os campos de busca. Dos resultados obtidos, foram escolhidos treze trabalhos, entre artigos, teses e dissertações, por meio dos quais serão apresentadas e discutidas algumas questões relativas ao trabalho de cuidador residente e o estabelecimento de vínculos com as crianças e adolescentes acolhidos.

Os artigos escolhidos para discussão foram dois, quais sejam: "Perfil mediacional de mães sociais que atuam em instituições de acolhimento", de Tomás e Vectore, publicado em 2012; e "Sentidos de desacolhimento de mães sociais dos sistemas de casas lares”, de Teixeira e Villachan-Lyra, publicado em 2015. Dos demais trabalhos, há apenas uma tese de doutorado, qual seja: "Quando o ambiente é o abrigo: cuidando das cuidadoras de crianças em acolhimento institucional", de Careta, defendida em 2011.

Os outros dez textos selecionados são todos dissertações, elencadas a seguir com os respectivos autores e anos de publicação: "Ser mãe eu sei, o que falta agora é social: sobre o processo de constituição da identidade profissional no acolhimento institucional de crianças", de Lima (2009); "Conhecendo o perfil mediacional de mães sociais: um estudo sobre as interações em abrigos", de Tomás (2010); "Maternidade, missão e renúncia: um estudo sobre mães sociais", de Oliveira (2011); "Sentidos do vínculo afetivo para educadores de instituições de acolhimento: um estudo de caso", de Segui (2012); "Mães sociais: que profissão é essa?", de Ribeiro (2012); "Um olhar winnicotiano sobre o imaginário coletivo das mães sociais acerca do cuidado infantil na situação de abrigamento", de Ponce (2013); "Dimensões psicossociais das práticas de cuidado", de Pereira (2013); "Mediação pedagógica no acolhimento institucional e as práticas socioeducativas com crianças e adolescentes nas relações de conflitos”, de Ferreira (2014); "Compreensão de crianças em situação de acolhimento institucional acerca dos seus direitos", de Medeiros (2015); e "Desenvolvimento e avaliação de

\footnotetext{
${ }^{4}$ Disponível em: http://www.parthenon.biblioteca.unesp.br/.

${ }^{5}$ Disponível em: http://bdtd.ibict.br/vufind.

${ }^{6} \mathrm{O}$ uso de asterisco $\left({ }^{*}\right)$ possibilita a pesquisa por todos os termos que comecem com o radical pesquisado.
} 
impacto de intervenção preventiva para síndrome de burnout em cuidadores residentes", de Costa (2015).

\section{Resultados e discussão}

Tendo como foco as relações que se estabelecem nas casas-lares, envolvendo os cuidadores residentes, podemos observar que a maioria das pesquisas aponta, em algum momento, aspectos acerca da vivência dos cuidadores residentes junto às crianças e adolescentes que se encontram sob medida protetiva, apesar de apresentarem os mais diversos objetivos de investigação. Algumas trazem esse âmbito das relações e estabelecimento de vínculos como central na pesquisa, enquanto outras apenas a citam como um dos eixos necessários para discussão.

Em pesquisa realizada acerca das mediações estabelecidas entre mães sociais e crianças institucionalizadas, Tomás (2010) observou que, além da organização da casa e dos cuidados básicos com as crianças e adolescentes acolhidos, há um grande número de variáveis conferidas ao trabalho dessas mulheres, que é permeado por contradições, como: "as dificuldades em estabelecer vínculos que podem ser rompidos a qualquer instante e, ao mesmo tempo, da premência em se construir tais vínculos, haja vista a sua importância para a criança que está sob os seus cuidados" (p. 95).

De modo semelhante, Teixeira e Villachan-Lyra (2015) encontram nas falas das mães sociais entrevistadas uma alternância entre o papel de mãe das crianças acolhidas e o papel de profissional dedicada ao trabalho de cuidar. Essa realidade percebida com os sujeitos participantes de ambas as pesquisas, que caracteriza um paradoxo acerca do lugar que ocupam para os sujeitos sob sua responsabilidade, também aparece em outra pesquisa (Medeiros, 2015), na qual as cuidadoras assumiam-se mãe em determinadas situações e, ao mesmo tempo, afirmavam o lugar de profissional que ocupam. É o que podemos depreender, nas seguintes falas de uma mesma mãe social entrevistada na referida pesquisa:

\section{[...] a gente também não pode ultrapassar do nosso}

limite. Tem coisa que quem trata é I., A. [membros da equipe de acolhimento]. Na casa, a gente tem o total comando da casa [...] A gente tem que passar tudo a eles. Relatórios, a parte também deles. É um trabalho que tem que ser registrado. Tá tudo ali na pastinha deles [referindo-se às crianças] (p. 85).
E

[...] é um trabalho muito gratificante, já criei muitos filhos, já tenho netos. [...] Eles sempre vem me visitar, ontem ligaram pra mim, vem na minha casa (p. 87).

Ambas as falas, quando problematizadas juntamente com a seguinte, proferida pela mesma cuidadora, nos levam a pensar nas estratégias que essas mulheres desenvolvem para lidar com as situações próprias de sua função na casa-lar (Medeiros, 2015):

Agora a gente, nós funcionárias, já tá mais consciente, antes não, antes a gente sofria muito. O trabalho que elas [equipe de acolhimento] fazem com a gente deixa mais consciente, hoje eu sou mais consciente de que o bebê tem que estar com a mãe, tem que estar com a família, então hoje eu me sinto feliz, porque se a família quer, é porque ele tem muita importância pra família (p. 87).

A partir dessas primeiras colocações, podemos perceber a complexidade que perpassa o trabalho dessas mulheres, cujas atividades prezam pelo desenvolvimento de relações afetivas - sendo-lhe atribuídas funções de cuidado com outros sujeitos - mas, ao mesmo tempo, são atividades próprias da sua condição de trabalho, que exigem delas profissionalismo e um fazer técnico.

Ainda dentro dessa discussão, Costa (2015) identifica diversos papéis assumidos pelos cuidadores residentes, definindo-os como: "mãe/pai social para as crianças; cuidadores para a instituição e trabalhadores para o Estado" (p. 36). Para a autora, o trabalho de cuidador residente é altamente demandante e, quando associado à ambiguidade vivida acerca das atribuições e das expectativas das crianças, da instituição de trabalho e do Estado, aumenta-se a possibilidade de desenvolverem a síndrome de burnout, com desgaste psíquico, atitudes e comportamentos negativos, e sentimento de culpa.

O momento em que esse desgaste psíquico parece ficar mais evidente, em algumas pesquisas, é o do desligamento das crianças ou adolescentes acolhidos, exigindo um olhar mais atento a este processo. A fala de um dos educadores entrevistados por Segui (2012) ilustra bem essa situação: 
André. E uma criança que saiu daqui que eu sofri muito, muito, que eu fiquei numa situação, Fernanda, que eu fiquei tanto estressado... Eu fiquei até 'irritante', foi o Jason. Por que eu me apeguei tanto com ele, eu faço o possivel para não me apegar. Agora, no fundo, no fundo, estou me apegando com o Gabrielzinho. Não tem como você não se apegue. Então o Jason, era muito apegado muito apegado. [...] O desligamento é brabo, ébrabo, eu até graça dei de eu não estar aqui hoje, na hora que o outro "carrego" as coisas dele. Que no fundo, no fundo quando eles irrita, eles tem dia que te tira do sério, mas não tem quem você não goste. Se vocêfaz tudo o que você faz, você chama a atenção, você repreende, tem dia que vocêfala: "-Não quero que vocêfaça esse tipo de coisa!" No coração, no coração não adianta, sempre tem o amor, né? (p. 76, grifo nosso).

Mesmo havendo orientações específicas para capacitação, acompanhamento e orientação das cuidadoras residentes por parte da equipe técnica do serviço de acolhimento (Brasil, 2009), de forma a minimizar os impactos dessas situações e auxiliar no desenvolvimento de estratégias de enfrentamento, algumas pesquisadoras não encontraram, nas instituições investigadas, esse suporte profissional. Isso potencializa, nas cuidadoras, sentimentos de abandono, despreparo, desmotivação, falta de capacitação para o trabalho, e também sofrimento psíquico ante as condições reais de atuação (Careta, 2011; Ferreira, 2014; Tomás, \& Vectore, 2012).

Quanto às atribuições profissionais esperadas, vemos na pesquisa de Ribeiro (2012), na cidade de Curitiba e região, que ela encontrou anúncios de emprego que não tinham sequer atenção cuidadosa aos critérios de seleção ou à capacitação, regulamentados por lei para cumprimento da função. Entendemos que essa questão merece a devida atenção, posto que o trabalho realizado pelos cuidadores residentes exige não só profissionalmente dos sujeitos, que apresentam muitas atribuições e longas jornadas de trabalho, mas também demanda profissionalismo ante os fatores emocionais e afetivos que permeiam o seu fazer.

Quando enfocamos as relações afetivas que se dão nas instituições de acolhimento, mais uma questão passa a ser incorporada ao trabalho do cuidador residente. Levando em conta que o serviço de acolhimento deve ser temporário e que os demais serviços da assistência social devem ser acionados com vistas à reinte- gração das crianças e adolescentes acolhidos para sua família no menor tempo possível, enquanto estão sob responsabilidade dos cuidadores residentes, alguns sujeitos recebem periodicamente a visita de mães, avós, ou outros familiares na instituição de acolhimento.

Tendo em vista que a reintegração familiar é o principal objetivo a ser alcançado pela rede, nesse processo, os cuidadores devem não apenas receber estes familiares no espaço da casa-lar, como incentivar e estimular a manutenção dos vínculos familiares das crianças e adolescentes temporariamente sob seus cuidados. Essa questão, no entanto, pode levar a uma dualidade de sentimentos nos próprios cuidadores, como percebemos em pesquisas anteriormente citadas (Medeiros, 2015; Teixeira \& Villachan-Lyra, 2015; Tomás, 2010) e também na pesquisa realizada por Careta (2011), seja pelo afeto que desenvolvem na relação com os sujeitos acolhidos, ou por uma conjugação de fatores que permeiam essas relações entre cuidadores, acolhidos e familiares.

No grupo terapêutico no qual desenvolveu sua pesquisa, Careta (2011) encontrou muitos relatos de dificuldades de relacionamento entre cuidadoras e as famílias das crianças acolhidas, não só por acreditarem que as crianças estão melhor no espaço do acolhimento, mas pela responsabilidade que carregam sobre seus ombros:

O grupo comenta no geral sobre a dificuldade de relacionamentos. Nivea aborda o quanto é difícil receber as mães durante as visitas a seus filhos no abrigo, evidentemente aquelas que são autorizadas judicialmente. Revela que as mães procuram marcas pelo corpo das crianças para responsabilizar as cuidadoras por maus-tratos. A rivalidade se apresenta. Outras cuidadoras incentivam o discurso de Nivea. Citam que não dormem à noite e levantam para atender às crianças, ora para ministrar remédios, ora para alimentar os bebês. Levam ao médico e à escola. [...]. Os sentimentos de domínio e posse configuram-se no grupo. As disputas e rivalidades apresentam-se atreladas à confusão de papéis: do cuidador e de mãe (Careta, 2011, p. 129-130).

Em contrapartida, há também pesquisas que encontraram relações de apoio entre cuidadoras e familiares, porém com ênfase nas implicações desse encontro e parceria para o bem-estar e melhor desenvolvimento dos sujeitos acolhidos, e não das pessoas que ocupam o papel de cuidador. Na pesquisa de 
Medeiros (2015), as mães sociais ressaltaram a importância da relação de proximidade com a família biológica, tanto para obterem informações acerca das crianças recém-acolhidas, quanto pela felicidade que expressam ao verem "a mãe deles ser amiga da gente (cuidadoras)" (p. 89).

Diante da importância de relações estáveis e afetivas para o desenvolvimento das crianças, o estabelecimento de vínculos entre cuidadores, acolhidos e famílias biológicas, se torna um elemento a ser problematizado nas instituições de acolhimento, posto que o ser humano necessita do outro com quem se vincula para seu desenvolvimento e constituição enquanto sujeito (Rossetti-Ferreira et al., 2012), sendo as relações de mediação estabelecidas com o outro essenciais para os processos de aprendizagem e desenvolvimento individual (Vygotsky, 1991).

Oliveira (2011) destaca ainda a importância do desenvolvimento de relações de qualidade entre as crianças e adolescentes acolhidos na mesma instituição:

A partir da criação desses vínculos significativos a relação entre os adolescentes e as crianças são interpretados e colocados pelas mães sociais como entre irmãos reforçados e acentuados através da convivência diária e a rotina da casa.

Eu tento passar pra eles que todos que estão aqui dentro são irmãos, e é como uma família né, até que cada um volte pra sua. A gente tem que construir isso aqui, porque senão fica complicada a convivência, entendeu. $\mathrm{E}$ assim a gente tenta, e tem aquelas confusões de irmão mesmo, mas depois desculpam aí começam a se agarrar; eu procuro formar uma família; às vezes a gente consegue, tem coisa que a gente consegue que sinta mesmo dentro de uma família (p. 89, grifo nosso).

O trecho em destaque, na citação acima, quando pensado a partir da discussão até então realizada, nos leva a questionar até que ponto seria saudável para o desenvolvimento desses sujeitos a tentativa de criação de um espaço familiar ideal dentro da instituição de acolhimento, ao invés de se trabalhar a organização, inclusive afetiva, daquele espaço como diferenciado do espaço familiar, mas que cumpre as funções de cuidado e atenção necessários no período de permanência dos sujeitos acolhidos.

A pesquisa desenvolvida por Teixeira e Villachan-Lyra (2015) apontou que todas as mães sociais entrevistadas declararam conduzir suas atividades a partir do "afeto", além de expressarem com frequência um sentimento maternal em relação às crianças institucionalizadas: "é a partir dele [do afeto] que se consegue chegar às realidades individuais de criança e que o trabalho se torna possível" (p. 205). De modo semelhante, as mães sociais entrevistadas por Lima (2009), significam o afeto para com as crianças no cotidiano da instituição, expressando-o ao "beijá-las, abraçá-las e oferecer colo; preparar um lanche saboroso, flexibilizar as regras e se divertir junto" (p. 151).

A compreensão dessas relações afetivas enquanto modalidade de cuidado se faz presente ainda na pesquisa de Pereira (2013), ressalvando-se o fato que, apesar de as mães sociais por ela pesquisada entenderem as ações de cuidado para além das necessidades básicas e verbalizarem interesse em ter maior participação na vida dos sujeitos acolhidos, percebem que a dinâmica da prática cotidiana das casas lares não lhes possibilita fazê-lo.

Ferreira (2014) nos apresenta uma outra perspectiva acerca do estabelecimento (ou não) de relações afetivas ante o exercício da função de cuidadores. Em suas observações, destaca o abandono e desesperança que pode perceber no ambiente de acolhimento por ela investigado, com indagações pertinentes: "O afeto era algo ausente ali, em todos, inclusive nos(as) cuidadores(as) que também estavam necessitados(as) de afeto. Como poderão dar aquilo que não têm? De que forma dar carinho quando se está tão carente de infraestrutura, incentivo psicológico, político e social?" (p. 65).

A isto, a autora articula a frustração vivenciada pelos cuidadores em relação a regras recebidas "de cima" para serem praticadas nas casas-lares sob sua responsabilidade, bem como em relação à ausência da equipe técnica nesses espaços, colocada por um dos cuidadores como necessária "justamente para auxiliar nas tensões das quais os(as) cuidadores(as) não conseguissem dar conta por estarem ligados a fatores de uma demanda mais emocional" (Ferreira, 2014, p. 82).

Essas situações de ambivalência em relação à prática e à afetação própria ao trabalho realizado aparecem também em outras pesquisas já citadas. Ponce (2013), ao abordar essa questão, destaca a demanda emocional cotidianamente vivenciada pelas cuidadoras: 
No momento em que esta participante aborda o sofrimento infantil relatado pelas próprias crianças, todas as cuidadoras concordam que esta é a parte mais complicada do trabalho.

Uma terceira mãe social ressalta ser necessário muita "estrutura emocional" para lidar com esse conteúdo, e comenta sobre uma conhecida que desistiu do emprego por não aguentar lidar com tamanho sofrimento. Ela encerra seu relato dizendo que apesar da primeira impressão ser chocante, se mantém no trabalho graças ao vínculo afetivo que estabeleceu com os institucionalizados, pensando neles até mesmo quanto está de folga com seus próprios filhos (p. 106-107).

O tensionamento existente entre o cumprimento de um fazer profissional e o estabelecimento de relações afetivas se faz constantemente presente nas falas dos cuidadores ao se referirem ao seu trabalho, nas diferentes pesquisas realizadas e analisadas para comporte este artigo. Diante disso, surgem questionamentos acerca da preparação profissional a qual são submetidos aqueles que assumem a função de cuidadores em instituições de acolhimento, bem como do acompanhamento técnico necessário ao longo do desenvolvimento desta função.

As pesquisas já realizadas explicitam o quanto este trabalho demanda, não só em termos de atribuições técnicas, mas emocionalmente, fazendo-nos perceber que não se trata apenas de ter atenção ao desenvolvimento integral dos sujeitos acolhidos quando da avaliação dos serviços de acolhimento. Se faz necessário atentar também ao desenvolvimento emocional e processos de adoecimento pelos quais passam os responsáveis pelos cuidados a esses sujeitos, inclusive pelas implicações que isso tem nas relações diretas estabelecidas com aqueles sob medida protetiva, como explicita Ferreira (2014).

\section{Considerações finais}

Inserido em uma pesquisa mais ampla, o presente trabalho objetivava discutir aspectos inerentes ao trabalho de cuidadores residentes, em especial as vivências que perpassam sua atuação. Essa discussão introdutória, por sua vez, trouxe mais questionamentos e dúvidas que esclarecimentos.

Observamos, a partir da leitura e análise dos trabalhos já produzidos acerca da temática, a diver- sidade de arranjos institucionais e particularidades das vivências de cada cuidador entrevistado. Apesar de haver uma série de documentos que funcionam como orientadores da organização desses serviços, eles não abarcam a concretude da realidade vivenciada por aqueles que fazem a instituição, apontando de forma superficial algumas questões, por exemplo, acerca da jornada de trabalho a ser cumprida pelos cuidadores, o que possibilita diferentes interpretações por instituição.

Destacamos também as contradições vivenciadas por estes profissionais. Várias são as pesquisas (Lima, 2009; Medeiros, 2015; Oliveira, 2011; Tomás, 2010) em que os sujeitos entrevistados apresentam falas contraditórias, apontando a relação maternal e afetiva para com as crianças acolhidas e, no momento seguinte, o papel profissional e a postura técnica que precisam assumir enquanto funcionárias.

Tomás (2010) aponta a urgência em se refletir sobre sua identidade profissional e pessoal posto que as cuidadoras residentes assumem profissionalmente um lugar de referência afetiva constante e um acompanhamento diário dessas crianças e adolescentes, assemelhando-se provisoriamente às funções parentais, ao mesmo tempo em que devem manter postura e visão técnicas. De forma a melhor ilustrar a necessidade de se discutir a temática, vale resgatar um trecho da pesquisa de Tomás (2010):

[...] o constante medo de se envolver afetivamente e seguir o rompimento, a perda de contato com a criança e sofrer por essa ausência ficaram muito evidentes. Com isso, fica um misto de sentimentos de desejo de que a criança seja adotada e tenha uma família em contraste com o sofrimento que isso pode acarretar "Aí, o juiz falou que a culpada disso somos nós, porque aqui tem que separar amor, carinho, vínculo, trabalho, nós somos funcionárias ... então a culpa do vínculo é nossa... então deveria ser feito um trabalho aqui dentro (p. 96).

Ficam aqui questionamentos acerca da complexidade do trabalho dos cuidadores residentes, acerca dos paradoxos que permeiam as vivências desses profissionais, para quem o envolvimento afetivo passa a ser uma atribuição de seu trabalho. Sobre as rupturas afetivas vivenciadas no espaço de acolhimento, o foco das discussões deve se dar em torno 
de como o sujeito e as pessoas com as quais ele convive significam a situação, e das vivências posteriores às rupturas afetivas diante das possibilidades de ressignificação dos eventos vividos (Rossetti-Ferreira, \& Costa, 2012).

Por fim, reconhecendo a importância de se ter atenção aos vínculos e rupturas vivenciados pelas crianças e adolescentes acolhidos, ressaltamos também a imprescindibilidade de se olhar para os vínculos estabelecidos pelos próprios cuidadores quando de seu exercício profissional, as rupturas dele decorrentes, os significados atribuídos às relações que derivam de seu fazer profissional e as implicações que terão para suas práticas posteriores.

\section{Referências}

Brasil (2005). Política Nacional de Assistência Social PNAS/2004. Norma Operacional Básica NOB/SUAS. Brasília, DF: Ministério do Desenvolvimento Social e Combate à Fome, Secretaria Nacional de Assistência Social. Recuperado de http://www.mds.gov.br/webarquivos/publicacao/assistencia_social/Normativas/PNAS2004.pdf.

Brasil (2006a). Plano Nacional de Promoção, Proteção e Defesa do Direito de Crianças e Adolescentes à Convivência Familiar e Comunitária - PNCFC. Brasília, DF: Ministério do Desenvolvimento Social e Combate à Fome, Secretaria Especial dos Direitos Humanos. Recuperado de http://www.sdh.gov.br/assuntos/criancas-e-adolescentes/ programas/pdf/plano-nacional-de-convivencia-familiar-e.pdf.

Brasil (2006b). Norma Operacional Básica de Recursos Humanos para o SUAS (NOB-RH/SUAS). Brasília, DF: Ministério do Desenvolvimento Social e Combate à Fome, Secretaria Nacional de Assistência Social. Recuperado de http://www.mds.gov.br/cnas/politica-e-nobs/nob-rh_08-08-2011.pdf.

Brasil (2009). Orientações técnicas: Serviços de Acolhimento para Crianças e Adolescentes. Brasília, DF: Conselho Nacional dos Direitos da Criança e do Adolescente/Conselho Nacional de Assistência Social. Recuperado de http://www.sdh.gov.br/assuntos/criancas-e-adolescentes/programas/pdf/orientacoes-tecnicas.pdf.

Brasil (2013). Tipificação Nacional de Serviços Socioassistenciais. Brasília, DF: Ministério do Desenvolvimento Social e Combate à Fome, Secretaria Nacional de Assistência Social. Recuperado de http://www.mds.gov.br/ webarquivos/publicacao/assistencia_social/Normativas/tipificacao.pdf.

Careta, D. S. (2011). Quando o ambiente é o abrigo: cuidando das cuidadoras de crianças em acolhimento institucional (Tese de doutorado). Instituto de Psicologia, Universidade de São Paulo, São Paulo, SP.

Constituição da República Federativa do Brasil de 1988. Recuperado de http://www.planalto.gov.br/ccivil_03/ Constituicao/Constituicao.htm

Côrrea, M. (1997). A cidade de menores: uma utopia dos anos 30. In M. C. Freitas (Org.), História social da infância no Brasil. (pp. 77-96). São Paulo, SP: Cortez.

Costa, N. R. A., \& Rossetti-Ferreira, M. C. (2009). Acolhimento familiar: uma alternativa de proteção para crianças e adolescentes. Psicologia: Reflexão e Crítica, 22(1), 111-118. https://doi.org/10.1590/S0102-79722009000100015

Costa, V. S. (2015). Desenvolvimento e avaliação de impacto de intervenção preventiva para síndrome de Burnout em cuidadores residentes (Dissertação de mestrado). Faculdade de Psicologia, Pontifícia Universidade Católica do Rio Grande do Sul, Porto Alegre, Rio Grande do Sul.

Faleiros, V. P., \& Faleiros, E. S. (2007). Escola que protege: Enfrentando a violência contra crianças e adolescentes. Brasília, DF: Ministério da Educação, Secretaria de Educação Continuada, Alfabetização e Diversidade.

Ferreira, F. C. (2014). Mediação pedagógica no acolhimento institucional e as práticas socioeducativas com crianças e adolescentes nas relações de conflitos. (Dissertação de mestrado). Programa de Pós-Graduação em Educação, Universidade Vale dos Sinos, São Leopoldo, Rio Grande do Sul.

Lei $N^{o}$ 7.644, de 18 de dezembro de 1987. Dispõe sobre a Regulamentação da Atividade de Mãe Social e dá outras providências. Recuperado de http://www.planalto.gov.br/ccivil_03/leis/L7644.htm.

Lei No 8.069, de 13 de julho de 1990. Dispõe sobre o Estatuto da Criança e do Adolescente e dá outras providências. Recuperado dehttp://www.planalto.gov.br/ccivil_03/leis/L8069.htm

Lima, A. O. M. N. (2009). Ser mãe eu sei, o que falta agora é social: Sobre o processo de constituição da identidade profissional no acolhimento institucional de crianças (Dissertação de mestrado). Instituto de Psicologia, Universidade Federal de Uberlândia, Uberlândia, Minas Gerais. 
Marcilio, M. L. (1997). A roda dos expostos e a criança abandonada na história do Brasil: 1726-1950. In M. C. Freitas (Org.), História social da infância no Brasil. (pp. 51-76). São Paulo, SP: Cortez.

Medeiros, B. C. D. (2015). A compreensão de crianças em situação de acolhimento institucional acerca dos seus direitos (Dissertação de mestrado). Programa de Pós-Graduação em Psicologia, Universidade Federal do Rio Grande do Norte, Natal, Rio Grande do Norte.

Oliveira, D. R. (2011). Maternidade, missão e renúncia: um estudo sobre mães sociais (Dissertação de mestrado). Instituto de Psicologia, Universidade do Estado do Rio de Janeiro, Rio de Janeiro, Rio de Janeiro.

Organização das Nações Unidas - ONU. (2007). Projeto de diretrizes das Nações Unidas sobre emprego e condições adequadas de cuidados alternativos com crianças. Recuperado de http:/ /www.neca.org.br/programas/ivdiretrizes.pdf.

Organização das Nações Unidas - ONU. (2009). Diretrizes de cuidados alternativos à criança. Recuperado de http:// www.neca.org.br/images/apresent._II\%20seminario/Guidelines\%20Portuguese\%20-\%200NU\%20CUIDADOS\%20ALTERNATIVOS\%20(1).pdf.

Pereira, A. M. S. (2013). Dimensões psicossociais das práticas de cuidado (Dissertação de mestrado). Universidade Federal do Paraná, Curitiba, Paraná.

Perez, J. R. R., \& Passone, E. F. (2010). Políticas sociais de atendimento às crianças e aos adolescentes no Brasil. Cadernos de Pesquisa, 40(140), 649-673. https://doi.org/10.1590/S0100-15742010000200017

Ponce, L. G. (2013). Um olhar winnicottiano sobre o imaginário coletivo das mães sociais acerca do cuidado infantil na situação de abrigamento (Dissertação de mestrado). Departamento de Psicologia, Pontifícia Universidade Católica de São Paulo, São Paulo, São Paulo.

Portaria № 397, de 9 de outubro de 2002. Aprova a Classificação Brasileira de Ocupações - CBO/2002, para uso em todo território nacional e autoriza a sua publicação e revoga a portaria que menciona. Recuperado de http:// www.mtecbo.gov.br/cbosite/pages/legislacao.jsf.

Ribeiro, T. (2012). Mães sociais: que profissão é essa? (Dissertação de mestrado). Universidade Federal do Paraná, Curitiba, Paraná.

Rosemberg, F., \& Mariano, C. L. S. (2010). A Convenção Internacional sobre os Direitos da Criança: debates e tensões. Cadernos de Pesquisa, 40(141), p.693-728. https://doi.org/10.1590/S0100-15742010000300003

Rossetti-Ferreira, M. C., \& Costa, N. R. A. (2012). Construcción de vínculos afectivos en contextos adversos de desarrollo: Importancia y polémicas. Scripta Nova, 16(395). Recuperado de http://www.ub.edu/geocrit/sn/sn-395/sn-395-2.htm

Rossetti-Ferreira, M. C., Almeida, I. G., Costa, N. R. A., Guimarães, L. A., Mariano, F. N. Teixeira, S. C. P., \& Serrano, S. A. (2012). Acolhimento de crianças e adolescentes em situações de abandono, violência e rupturas. Psicologia: Reflexão e Crítica, 25(2), 390-399. https://doi.org/10.1590/S0102-79722012000200021

Segui, F. A. C. (2012). Sentidos do vínculo afetivo para educadores de instituições de acolhimento: um estudo de caso (Dissertação de mestrado). Departamento de Psicologia, Pontifícia Universidade Católica de São Paulo, São Paulo, São Paulo.

Teixeira, P. A. S., \& Villachan-Lyra, P. (2015). Sentidos de desacolhimento de mães sociais dos sistemas de casas lares. Psicologia \& Sociedade, 27(1), 199-210. https://doi.org/10.1590/1807-03102015v27n1p199

Tomás, D. N. (2010). Conhecendo o perfil mediacional de mães sociais: um estudo sobre as interações em abrigos (Dissertação de mestrado). Instituto de Psicologia, Universidade Federal de Uberlândia, Uberlândia, Minas Gerais.

Tomás, D. N., \& Vectore, C. (2012). Perfil mediacional de mães sociais que atuam em instituições de acolhimento. Psicologia: Ciência e Profissão, 32(3), 576-587. https://doi.org/10.1590/S1414-98932012000300005

Vygotsky, L. S. (1991). A formação social da mente. São Paulo, SP: Martins Fonte.

Blenda Carine Dantas de Medeiros

Mestre em Psicologia pela Universidade Federal do Rio Grande do Norte (UFRN). Doutoranda pelo Programa de Pós-Graduação em Psicologia da Universidade Estadual Paulista (Unesp), Assis - SP. Brasil. Bolsista da Fundação de Amparo à Pesquisa do Estado de São Paulo (FAPESP, processo no 2016/09622-2).

E-mail: blenda_carine@hotmail.com 


\section{João Batista Martins}

Docente da UniversidadeEstadual de Londrina(UEL), Londrina-PR. Brasil. Docente do Programa dePós-Graduação em Psicologia da Universidade Estadual Paulista (Unesp), Assis - SP. Brasil.

E-mail: jbmartin@sercomtel.com.br

Endereço para envio de correspondência:

Programa de Pós-Graduação em Psicologia (PPGPsi/FCL/UNESP-Assis).

Av. Dom Antônio, 2100, Parque Universitário, CEP: 19806-900. Assis - SP. Brasil.

Recebido 20/07/2017

Reformulado 23/10/2017

Aprovado 14/11/2017

Received $07 / 20 / 2017$

Reformulated 10/23/2017

Approved 11/14/2017

Recibido 20/07/2017

Reformulado 23/10/2017

Aceptado 14/11/2017

Como citar: Medeiros, B. C. D., \& Martins, J. B. (2018). O estabelecimento de vínculos entre cuidadores e crianças no contexto das instituições de acolhimento: Um estudo teórico. Psicologia: Ciência e Profissão, 38(1), 74-87. https://doi.org/10.1590/1982-3703002882017

How to cite: Medeiros, B. C. D., \& Martins, J. B. (2018). The establishment of bond between caregivers and children in the context of fostering institutions: A theoretical study. Psicologia: Ciência e Profissão, 38(1), 74-87. https://doi.org/10.1590/1982-3703002882017

Cómo citar: Medeiros, B. C. D., \& Martins, J. B. (2018). El establecimiento de vínculos entre cuidadores y niños en el contexto de las instituciones de acogida: Un estudio teórico. Psicologia: Ciência e Profissão, 38(1), 74-87. https://doi.org/10.1590/1982-3703002882017 